\title{
ANALISIS PENGARUH PENGGUNAAN FLY ASH DAN KAPUR TOHOR PADA PENETRALAN PH AIR ASAM TAMBANG DI PT. MANDIANGIN BARA PRIMA
}

\author{
Riam Marlina Amsya ${ }^{1)}$, Rizto Salia Zakri ${ }^{2}$, dan Muhammad Rofiq Fikri ${ }^{1)}$ \\ ${ }^{13}$ Teknik Pertambangan Sekolah Tinggi Teknologi Industri Padang, ${ }^{2}$ Teknik Pertambangan \\ Universitas Negeri Padang \\ Coresponding Email: riztoszakri@ft.unp.ac.id
}

\begin{abstract}
Abstrak
Abstrak : PT. Mandiangin Bara Prima merupakan perusahaan bergerak dibidang pertambangan batubara yang berdiri pada tahun 2005 dan merupakan salah satu perusahaan yang terletak di Kecamatan Pauh, Kabupaten Sarolangun, Provinsi Jambi. Air asam tambang merupakan permasalahan yang terjadi di pertambangan batubara, tidak terkecuali di PT. Mandiangin Bara Prima. Penanganan yang tepat menjadi sangat penting mengingat dampak dari AAT sangat berbahaya terhadap masyarakat, penanganan yang kurang tepat dari perusahaan juga dapat menimbulkan kenaikan biaya yang signifikan terhadap perusahaan. Tujuan dari penelitian ini adalah menganalisis efektifitas peggunaan kapur tohor dan fly ash untuk menetralkan $\mathrm{pH}$ air asam tambang serta menganalisis jumlah kebutuhan kapur tohor serta fly ash dan biaya yang yang dibutuhkan. Penelitian dilakukan di laboratotium Balai Riset dan Standardisasi Industri Padang, sampel air diambil pada inlet 1 dan inlet 2 kolam pengendapan PT. Mandiangin Bara Prima, selanjutnya dibawa dan diteliti di laboratorium. Fly ash dan kapur tohor ditambahkan pada masing-masing sampel air dengan komposisi yang berbeda sehingg didapatkan komposisi efektif dari penggunaan media tersebut. Dari hasil penelitan didapatkan Perubahan setelah ditambahkan kapur tohor pada inlet 1 mengalami kenaikan nilai $\mathrm{pH}$, perubahan sebesar 97\% Sedangkan pada inlet 2 kenaikan sebesar $75 \%$. Dan setelah ditambah fly ash pada inlet 1 mengalami kenaikan sebesar $64 \%$. Sedangkan pada inlet 2 mengalami kenaikan pH sebesar 56\%. Kebutuhan bahan penetral AAT untuk kapur tohor per bulan sebesar 410,28 Kg/bulan dengan biaya yang harus dikeluarkan sebesar Rp. 2.052.400,-/bulan dan fly ash sebanyak 2.630,7936 Kg/bulan.
\end{abstract}

Kata kunci : Air Asam Tambang, Fly Ash, Kapur Tohor, pH, Batubara

Abstract : PT. Mandiangin Bara Prima is a company engaged in coal mining which was established in 2005 and is one of the companies located in Pauh District, Sarolangun Regency, Jambi Province. Acid mine drainage is a problem that occurs in coal mining, including PT. Mandiangin Bara Prima. Proper handling is very important considering the impact of AAT is very dangerous to the community, improper handling by the company can also cause a significant increase in costs for the company. The purpose of this study was to analyze the effectiveness of using quicklime and fly ash to neutralize the $\mathrm{pH}$ of acid mine drainage and to analyze the amount of quicklime and fly ash needed and the costs involved. The study was conducted in the laboratory of the Padang Industrial Research and Standardization Institute, water samples were taken at inlet 1 and inlet 2 of the settling pond of PT. Mandiangin Bara Prima, then brought and examined in the laboratory. Fly ash and quicklime were added to each water sample with different compositions so that the effective composition of the media was obtained. From the results of the study, it was found that after adding quicklime to inlet 1 , the $\mathrm{pH}$ value increased, the change was $97 \%$, while at inlet 2 the increase was $75 \%$. And after adding fly ash at inlet 1, it increased by 64\%. While at inlet 2 the $\mathrm{pH}$ increased by 56\%. The need for AAT neutralizer for quicklime per month is $410.28 \mathrm{Kg} /$ month with a cost of Rp. 2,052,400,-/month and fly ash as much as 2,630,7936 Kg/month.

Keywords: Acid Mine Drainage, Fly Ash, Quicklime, PH, Coal 


\section{PENDAHULUAN}

PT. Mandiangin Bara Prima merupakan perusahaan bergerak dibidang pertambangan batubara yang berdiri pada tahun 2005 dan merupakan salah satu perusahaan yang terletak di Kecamatan Pauh, Kabupaten Sarolangun, Provinsi Jambi. PT. Mandiangin Bara Prima menggunakan sistem tambang terbuka dengan open pit mining.

Salah satu dampak negatif dari proses penambangan adalah timbulnya air asam tambang. Air Asam Tambang (AAT) atau Acid Mine Drainage (AMD) adalah air pada kegiatan penambangan atau pengolahan yang bersifat asam atau memiliki keasaman tinggi dan terbentuk sebagai akibat teroksidasinya mineral sulfida disertai keberadaan air (Gautama, 2019). Penanganan air asam tambang yang tidak tepat, bisa memunculkan bahaya terhadap lingkungan pda komposisi tertentu, ini disebabkan hasil oksidasi sulfida akan terangkut oleh aliran air yang menyebabkan lingkungan menajadi tercemar. Untuk mengatasi masalah di atas, maka perlu dilakukan pengolahan terhadap air asam tambang agar tidak membahayakan lingkungan di sekitarnya (Nasir, 2014).

PT. Mandiangin Bara Prima melakukan pengelolaan air asam tambang dengan cara mengalirkan air asam tambang ke dalam kolam-kolam pengendapan, ini mengacu pada KepMen Negara Lingkungan Hidup No. 113 Tahun 2003, Tentang Baku Mutu Air Limbah Bagi Usaha dan Kegiatan Pertambangan Batubara.

Standar bakumutu lingkungan sesuai dengan Keputusan Mentri Negara Lingkungan Hidup Nomor 113 Tahun 2003 diantaraanya meliputi keasaman $(\mathrm{pH})$ dengan batas kadar 6-9, Total Suspended Solid (TSS) dengan batas kadar 400mg/l, Besi (Fe) dengan batas kadar $7 \mathrm{mg} / \mathrm{l}$ dan Mangan (Mn) dengan batas kadar 4 mg/l.

Indikasi air asam tambang yang ada di PT. Mandiangin Bara Prima dapat diketahui dengan adanya air limbah keruh berwarna kecoklatan dan coklat kemerahan. Hal ini dikarenakan air limbah dalam lubang tambang umumnya telah tercampur dengan berbagai pengotor seperti tanah, pasir, batuan serta lumpur yang akan mempengaruhi tingginya nilai Total Suspended Solid.

Setelah dilakukan pengujian di laboratorium Balai riset dan standardisasi Industri Padang hasil kualitas air asam tambang yang ada di stasiun 1 atau inlet 1 pada PT. Mandiangin Bara Prima untuk parameter $\mathrm{pH}$ belum memenuhi baku mutu dimana nilai $\mathrm{pH}$ pada air asam tambang di inlet 1 adalah sebesar 4,8 , sedangkan pada inlet 2 untuk parameter $\mathrm{pH}$, juga belum memenuhi baku mutu, dimana nilai $\mathrm{pH}$ pada air asam tambang di inlet 2 adalah sebesar 5,5.

Inlet adalah tempat mengalirnya air dari tambang menuju kolam pengendapan. Inlet pada PT. Mandiangin Bara Prima memiliki lebar 2 meter dan tinggi $9 \mathrm{~cm}$. karena air yang berasal dari area penambangan akan diendapkan di kolam pengendapan maka dari penulis melakukan penelitian berupa upaya pemurnian air asam tambang yang ada di setling pond dengan panjang 9,5 meter, lebar 5 meter dan tinggi 2 meter agar parameter TSS, Fe dan Mn lebih baik lagi dengan dengan cara menambahkan bahan kimia yang bersifat basa. Bahan kimia yang digunakan untuk netralisasi ini adalah kapur tohor dan fly ash.

Kapur tohor $(\mathrm{CaO})$ adalah bahan yang paling umum digunakan untuk mengolah air asam tambang, karena kapur tohor termasuk salah satu bahan kimia yang dapat meningkatkan $\mathrm{pH}$ secara praktis, murah dan aman, serta dapat mengurangi kandungan logam berat yang terkandung dalam air asam tambang. Abu terbang (fly ash) umumnya bersifat alkalin dialam namun $\mathrm{pH}$ abu terbang dapat bervariasi dari 4,5-12. Nilai $\mathrm{pH}$ abu terbang sebagian ditentukan oleh kandungan sulfur dalam bahan induk batubara dan kandungan sulfur dalam abu terbang. 
Penetralan memanfaatkan kapur tohor sebagai media alkali penetralan. Pada kegiatan penetralan yang dilakukan PT. Mandiangin Bara Prima secara aktif belum menentukan jumlah kapur tohor yang efektif yang dibutuhkan untuk menetralkan air asam tambang, selain itu media fly ash belum pernah digunakan sebagai salah satu media penetralan, hal ini dikarenakan belum adanya penelitian lebih lanjut yang ada di perusahaan terkait sebagai acuan penggunaan media fly ash sebagai media tambahan untuk menetralkan air asam tambang.

\section{METODE PENELITIAN}

Dalam penelitian ini penulis menggunakan jenis penelitian terapan (applied research). Penelitian terapan adalah penelitian yang dikerjakan dengan maksud untuk menerapkan, menguji, dan mengevaluasi kemampuan suatu teori yang diterapkan dalam pemecah permasalahan teknis.

Penelitian terapan ini bertujuan untuk menemukan pengetahuan yang secara praktis dapat diaplikasikan. Hasil dari penelitian yang dilakukan tidak perlu sebagai suatu penemuan baru, akan tetapi merupakan aplikasi yang baru dari penelitian yang telah ada.

\section{Data dan Sumber Data}

Jenis data yang diperlukan dalam penelitian ini dalah sebagai berikut:

Data primer adalah data yang diukur dan dikumpulkan langsung sendiri dilapanagan, yaitu:

1. Koordinat pengambilan sampel

2. $\mathrm{pH}$ air

3. Debit air

Data sekunder adalah data yang
telah tersedia
perusahaan,yaitu:

1. Peta IUP dari perusahaan.

2. Peta kesampaian daerah.

3. Peta geologi regional.

4. Kepmen LH No 113 Tahun 2003

\section{Teknik Pengumpulan Data}

Teknik pengumpulan data melakukan pengukuran secara langsung di lapangan yaitu:

1. Pengujianinsitu di masing-masing stasiun pengamatan untuk mendapatkan nilai $\mathrm{pH}$ yang ditabulasi.

2. Perhitungan debit air dengan cara pengukuran kecepatan aliran air dan pengukuran luas area yang dialiri air

\section{Tahapan Penelitian}

\section{a. Pengukuran PH}

$\mathrm{pH}$ adalah derajat keasaman yang digunakan untuk menyatakan tingkat keasaman atau kebasaan yang dimiliki oleh suatu larutan. $\mathrm{pH}$ sendiri memeliki nilai yang berkisar antar 0-14

Istilah pH berasal dari "p", lambang matematika dari negatif logaritma, dan " $\mathrm{H}$ ", lambang kimia untuk unsur Hidrogen. Definisi yang formal tentang $\mathrm{pH}$ adalah negative logaritma dari aktifitas ion hydrogen dengan kata lain $\mathrm{pH}$ dapat dirumuskan sebagai berikut : $\mathrm{pH}=-\mathrm{Log}[\mathrm{H}+] \cdot \mathrm{pH}$

Dibentuk dari informasi kuantitatif yang dinyatakan oleh tingkat derajat keasaman atau basa yang berkaitandengan aktivitas ion hydrogen.

Nilai $\mathrm{pH}$ dari suatu unsur adalah perbandingan antara konsentrasi ion hydrogen $[\mathrm{H}+]$ dengan kosentrasi ion hidroksil [OH-]. Jika kosentrasi $\mathrm{H}+$ lebih besar dari $\mathrm{OH}-$, material disebut asam, yaitu nilai $\mathrm{pH}$ adalah kurang dari 7. Jika kosentrasi $\mathrm{OH}-$ lebih besar dari $\mathrm{H}+$, material disebut basa, yaitu nilai $\mathrm{pH}$ besar dari 7 .

Jika kosentrasi $\mathrm{H}+$ sama dengan $\mathrm{OH}-$ maka material disebut sebagai material netral. Asam dan basa mempunyai ion hydrogen bebas dan ion alkali bebas.Besarnya kosentrasi ion $\mathrm{H}+$ dalam larutan disebut derajat keasaman.Untuk menyatakan derjat keasaman suatu larutan dipakai pengertian $\mathrm{pH}$.

Atas dasar pengertian ini, ditentukan : 
a) jika nilai $\mathrm{pH}=\mathrm{pOH}=7$, maka larutan bersifat netral.

b) jika nilai $\mathrm{pH}<7$, maka larutan bersifat asam.

c) jika nilai $\mathrm{pH}>7$, maka larutan bersifat basa.

Alat $\mathrm{pH}$ meter digital dapat dilihat pada gambar 1 berikut:

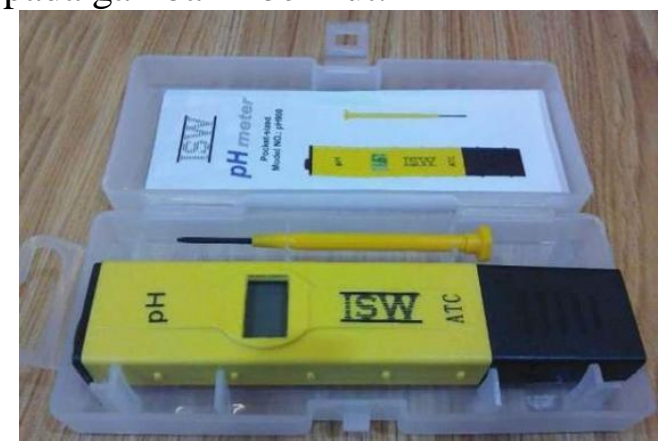

Gambar 1. Alat pH Meter Digital

\section{b. Standar Baku Mutu}

Baku mutu lingkungan menurut Undang-Undang Republik Indonesia Nomor 32 Tahun 2009 Tentang Perlindungan Dan Pengelolaan Lingkungan Hidup, adalah ukuran batas atau kadar makhluk hidup, zat, energi, atau komponen yang ada atau harus ada dan/atau unsur pencemar yang ditenggang keberadaannya dalam suatu sumber daya tertentu sebagai unsur lingkungan hidup.

Baku mutu lingkungan ini berfungsi sebagai indikator untuk menentukan terjadinya pencemaran lingkungan hidup. Sedangkan Baku mutu lingkungan hidup meliputi baku mutu air, baku mutu air limbah, baku mutu air laut, baku mutu udara ambien, baku mutu emisi, baku mutu gangguan, dan baku mutu lain sesuai dengan perkembangan ilmu pengetahuan dan teknologi.

Sedangkan baku mutu air limbah batubara menurut Keputusan Mentri Lingkungan Hidup Nomor 113 Tahun 2003 tentang baku mutu air limbah bagi usaha dan atau kegiatan pertambangan batubara, adalah ukuran batas atau kadar unsur pencemar dan atau jumlah unsur pencemaran yang ditenggang keberadaannya dalam air limbah batu bara yang akan dibuang atau dilepas ke air permukaan.

Berdasarkan fungsi baku mutu lingkungan, diperlukan cara untuk menentukan terjadi atau tidaknya pencemaran dari kegiatan industri, berikut ini merupakan dua sistem baku mutu lingkungan:

1. Effluent Standard, merupakan kadar maksimum limbah yang diperbolehkan untuk dibuang ke lingkungan.

2. Stream Standard, merupakan batas kadar untuk sumberdaya tertentu, seperti sungai, waduk, dan danau. Kadar yang diterapkan ini didasarkan pada kemampuan sumberdaya beserta sifat peruntukannya. Misalnya batas kadar badan air untuk air minum akan berlainan dengan batas kadar bagi badan air untuk pertanian.

Untuk lebih jelasnya dapat dilihat pada tabel 1 berikut:

Tabel 1. Baku Mutu Air Limbah Penambangan Batubara

\begin{tabular}{ccc}
\hline Parameter & Satuan & $\begin{array}{c}\text { Kadar } \\
\text { Maksimum }\end{array}$ \\
\hline pH & & $6-9$ \\
Residu Tersuspensi & $\mathrm{mg} / \mathrm{l}$ & 400 \\
Besi (Fe) Total & $\mathrm{Mg} / \mathrm{l}$ & 7 \\
Mangan (Mn) Total & $\mathrm{Mg} / \mathrm{l}$ & 4 \\
\hline Sumber: Keputusan & Mentri & Negara \\
Lingkungan Hidup Nomor & 113 Tahun 2003
\end{tabular}

Baku mutu air limbah Pengolahan atau Pencucian Batubara berdasarkan Keputusan Mentri Negara Lingkungan Hidup Nomor 113 Tahun 2003 dapat dilihat pada tabel 2 berikut:

Tabel 2 Baku Mutu Air Limbah Pengolahan atau Pencucian Batubara

\begin{tabular}{ccc}
\hline Parameter & Satuan & $\begin{array}{c}\text { Kadar } \\
\text { Maksimum }\end{array}$ \\
\hline $\mathrm{pH}$ & $\mathrm{mg} / \mathrm{l}$ & $6-9$ \\
Residu Tersuspensi & $\mathrm{Mg} / \mathrm{l}$ & 7 \\
Besi (Fe) Total & $\mathrm{Mg} / \mathrm{l}$ & 4 \\
Mangan (Mn) Total & Mentri & Negara \\
Sumber: Keputusan & Kahun 2003
\end{tabular}


Sehubungan dengan baku mutu lingkungan, ada istilah nilai ambang batas yang merupakan batas-batas daya dukung, daya tenggang dan daya toleransi atau kemampuan lingkungan. Nilai ambang batas tertinggi atau terendah dari kandungan zat-zat, makhluk hidup atau komponenkomponen lain dalam setiap interaksi yang berkenaan dengan lingkungan khususnya yang mempengaruhi mutu lingkungan. Jadi jika terjadi kondisi lingkungan yang telah melebihi nilai ambang batas (batas maksimum dan minimum) yang telah ditetapkan berdasarkan baku mutu lingkungan maka dapat dikatakan bahwa lingkungan tersebut telah tercemar.

\section{Penambahan Fly Ash dan Kapur Tohor}

Fly Ash Batubara adalah material yang memiliki ukuran butiran yang halus berwarna keabu-abuan dan diperoleh dari hasil pembakaran batubara (Wardani, 2008).

Produk dari pembakaran batubar di PLTU, berupa limbah dengan bentuk padatan yang terdiri atas abu layang ( Fly Ash) dan abu dasar bottom Ash. Sejalan dengan program meningkatkan produksi listrik di Indonesia, yang Sebagian besarnya menggunakan pembangkit listrik tenaga uap, maka ini juga akan meningkatkan produksi abu dasar dan abu terbang setiap tahunnya.

Dengan bertambahnya penumpukan abu tersebut maka perlu diusahakan untuk pemanfaatan limbah tersebut. Fly Ash batubara dapat dilihat pada gambar 2 berikut:

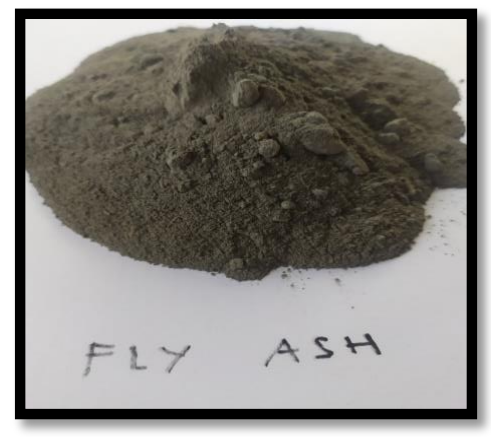

Gambar 2. Fly Ash
Fly Ash batubara umumnya bersifat alkalin di alam dan mengandung senyawa mineral utama yaitu kuarsa (SiO2) dan mullite (Al6Si2O13) yang berperan untuk menurunkan kadar logam dan air asam tambang.

Kapur Tohor memiliki warna putih serta berbentuk amorfos dengan rumus kimia CaO (Fuadi, 1999). Kapur tohor merupakan salah satu zat kimia yang paling umum digunakan dalam pengelolaan air asam tambang secara aktif, selain itu Kapur tohor merupakan zat kimia yang dapat dengan praktis, murah dan aman. Serta kapur tohor juga banyak digunakan untuk mengikat logam berat di alam.

Wuju dari kapur tohor dapat dilihat pada gambar 3 berikut:

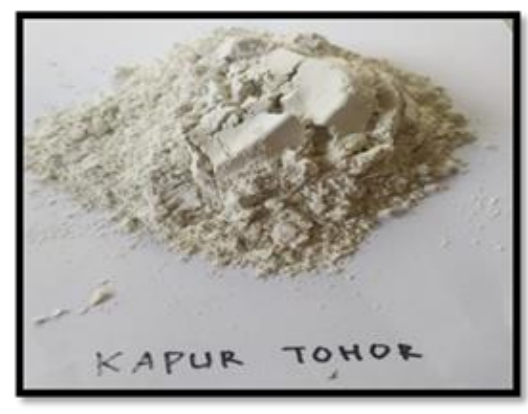

Gambar 3. Kapur Tohor

Untuk lebih jelasnya tergambar pada bagan alir berikut :

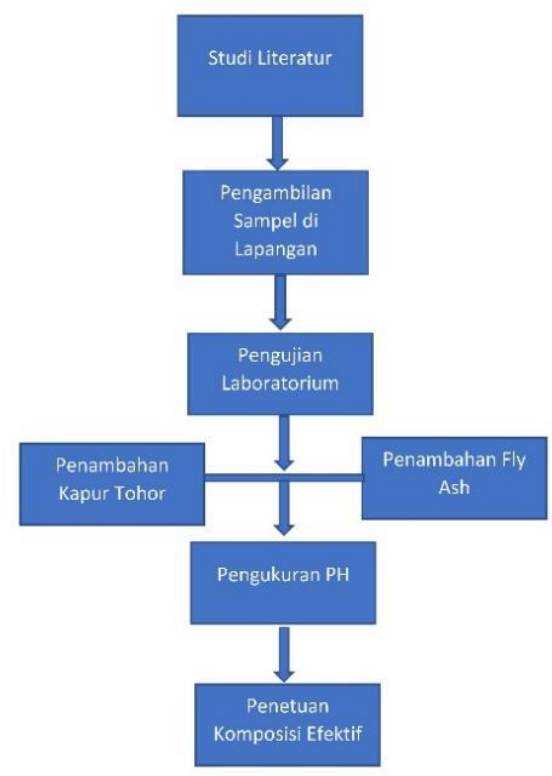

Gambar 4. Diagram Alir Penelitian 
HASIL DAN PEMBAHASAN

Perubahan pH Setelah Penambahan Kapur Tohor.

Perubahan nilai $\mathrm{pH}$ setelah dilakukan penambahan kapur tohor dengan jumlah $0.3 \mathrm{gr}, 0.4 \mathrm{gr}$, dan $0.5 \mathrm{gr}$ untuk masingmasing sampel 1,2, dan 3 adalah sebagai berikut :

Tabel 3. Perubahan PH Kapur Tohor

\begin{tabular}{ccccccc}
\hline $\begin{array}{c}\text { Tempat } \\
\text { Pengam } \\
\text { bilan } \\
\text { Sampel }\end{array}$ & $\begin{array}{c}\text { Sam } \\
\text { pel }\end{array}$ & pH & $\begin{array}{c}\mathrm{pH} \\
\text { Akhir }\end{array}$ & $\begin{array}{c}\text { Perub } \\
\text { ahan }\end{array}$ & $\begin{array}{c}\text { Rata-rata } \\
\text { Perubah } \\
\text { an }\end{array}$ & $\begin{array}{c}\mathrm{pH} \\
\text { rata- } \\
\text { rata }\end{array}$ \\
\hline \multirow{2}{*}{ Inlet 1 } & 1 & 4,8 & 7,8 & 3 & & \\
& 2 & 4,8 & 9,6 & 4,8 & 4,63 & 9,43 \\
& 3 & 4,8 & 10,9 & 6,1 & & \\
\hline \multirow{3}{*}{ Inlet 2 } & 1 & 5,5 & 8,0 & 2,5 & & \\
& 2 & 5,5 & 9,5 & 4 & 4,10 & 9,60 \\
\hline
\end{tabular}

Berdasarkan tabel diatas dapat disimpulkan bahwa terjadi kenaikan nilai $\mathrm{pH}$ pada setiap sampel pada masingmasing inlet. Pada inlet 1 rata-rata kenaikan nilai $\mathrm{pH}$ setelah ditambahkan kapur tohor adalah sebesar 4,63 sehingga nilai $\mathrm{pH}$ dari air asam tambang meningkat dari rata-rata $\mathrm{pH}$ 4,8 meningkat menjadi 9,43 . Sehingga air yang awalnya bersifat asam berubah menjadi basa.

Sedangkan pada inlet 2 rata-rata kenaikan nilai $\mathrm{pH}$ setelah ditambahkan kapur tohor adalah sebesar 4,10 sehingga nilai $\mathrm{pH}$ dari air asam tambang meningkat dari nilai pH 5,5 meningkat menjadi 9,60. Sehingga air yang awalnya bersifat asam berubah menjadi basa.

\section{Perubahan pH Setelah Penambahan Fly Ash}

Perubahan nilai $\mathrm{pH}$ setelah dilakukan penambahan Fly ash dengan jumlah 0.3gr, $0.4 \mathrm{gr}$, dan 0.5 gr untuk masing-masing sampel 1,2,dan 3 adalah sebagai berikut :

Tabel 4. Perubahan $\mathrm{pH}$ Fly Ash

\begin{tabular}{ccccccc}
\hline $\begin{array}{c}\text { Tempat } \\
\text { Pengam } \\
\text { bilan }\end{array}$ & $\begin{array}{c}\text { Sam } \\
\text { pel }\end{array}$ & pH & $\begin{array}{c}\text { pH } \\
\text { Akhir }\end{array}$ & $\begin{array}{c}\text { Perub } \\
\text { ahan }\end{array}$ & $\begin{array}{c}\text { Rata-rata } \\
\text { Perubah } \\
\text { an }\end{array}$ & $\begin{array}{c}\text { pH } \\
\text { rata- } \\
\text { rata }\end{array}$ \\
\hline \multirow{2}{*}{ Inlet 1 } & 1 & 4,8 & 7,0 & 2,2 & & \\
& 2 & 4,8 & 8,0 & 3,2 & 3,07 & 7,87 \\
& 3 & 4,8 & 8,6 & 3,8 & & \\
\hline \multirow{2}{*}{ Inlet 2 } & 1 & 5,5 & 7,6 & 2,1 & & \\
& 2 & 5,5 & 8,8 & 3,3 & 3,10 & 8,60 \\
\hline
\end{tabular}

Setelah ditambahkan fly ash pada inlet 1 rata-rata kenaikan nilai $\mathrm{pH}$ setelah ditambahkan fly ash adalah sebesar 3,07 sehingga nilai $\mathrm{pH}$ dari air asam tambang meningkat dari rata-rata $\mathrm{pH} \mathrm{4,8} \mathrm{meningkat}$ menjadi 7,87 . Sehingga air yang awalnya bersifat asam berubah menjadi netral. Sedangkan pada inlet 2 rata-rata kenaikan nilai $\mathrm{pH}$ setelah ditambahkan kapur tohor adalah sebesar 3,10 sehingga nilai $\mathrm{pH}$ dari air asam tambang meningkat dari nilai $\mathrm{pH}$ 5,5 meningkat menjadi 8,60. Dengan persentase kenaikan $\mathrm{pH}$ pada air asam tambang jika ditambahkan kapur tohor untuk inlet 1 adalah sebesar $97 \%$ dan pada inlet 2 sebesar 75\%. Sedangkan jika ditambahkan fly ash persentase kenaikan $\mathrm{pH}$ pada air asam tambang untuk inlet 1 adalah sebesar $64 \%$ dan pada inlet 2 sebesar $56 \%$. Sehingga air yang awalnya bersifat asam berubah menjadi netral. Berdasarkan hal tersebut dapat disimpulkan bahwa fly ash sangat efektif untuk digunakan pada kegiatan penetralan air asam tambang.

Perbandingan perubahan $\mathrm{pH}$ akibat penambahan kapur tohor dan penambahan fly ash dapat dilihat pada diagram berikut :

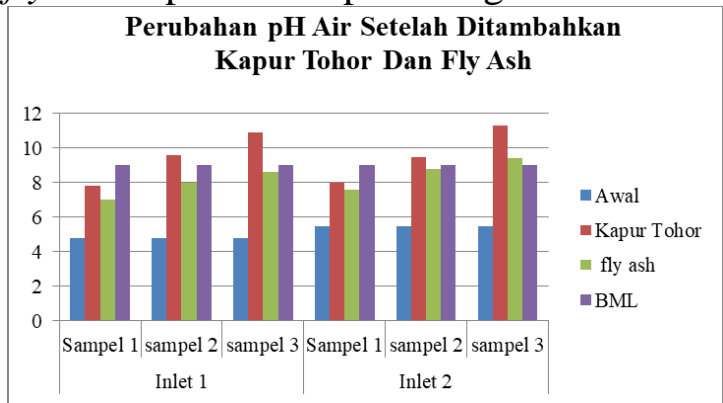

Gambar 5. Grafik Perubahan $\mathrm{pH}$ Air Setelah Ditambahkan Kapur Tohor Dan Fly Ash

Jumlah Kebutuhan Kapur Tohor dan Fly Ash per bulan

Rekapitulasi kebutuhan dan biaya yang diperlukan untuk penentralan air asam tambang dapat dilihat pada tabel 5 berikut:

Tabel 5. Rekapitulasi kebutuhan dan biaya

\begin{tabular}{|l|l|l|l|l|}
\hline Media & $\begin{array}{l}\text { Kebutuhan } \\
(\mathrm{kg})\end{array}$ & $\begin{array}{l}\text { Harga/kg } \\
(\mathrm{Rp})\end{array}$ & $\begin{array}{l}\text { Jumlah } \\
\text { Inlet }\end{array}$ & $\begin{array}{l}\text { Biaya yang } \\
\text { dibutuhkan }\end{array}$ \\
\hline $\begin{array}{l}\text { Kapur } \\
\text { Tohor }\end{array}$ & 410,28 & $\begin{array}{l}\mathrm{Rp} \\
2.500\end{array}$ & 2 & $\begin{array}{l}\text { Rp } \\
2.051 .400,-\end{array}$ \\
\hline $\begin{array}{l}\text { Fly } \\
\text { Ash }\end{array}$ & $2.630,79$ & \multicolumn{4}{|l}{} \\
\hline
\end{tabular}


Kebutuhan bahan penetral air asam tambang (AAT) dengan kapur tohor memerlukan total sebanyak 409,968 $\mathrm{Kg} / \mathrm{bulan}$ dengan biaya yang diperlukan adalah sebesar Rp.1.025.700.- perbulan untuk satu inlet, sedangkan untuk 2 inlet memerlukan biaya sebesar Rp. 2.051.400,perbulan.

Untuk kebutuhan fly ash yang direkomendasikan kepada perusahaan sebanyak $1.317,6 \mathrm{Kg} /$ bulan untuk satu inlet jika menggunakan 2 inlet maka kebutuhan fly ash adalah sebesar 2.630,7936 $\mathrm{kg} / \mathrm{bulan}$. Dan Biaya yang dibutuhkan untuk membeli fly ash dalam jumlah tersebut disesuaikan berdasarkan kesepakatan denganpihak PLTU setempat.

\section{KESIMPULAN}

Dari penelitian yang telah dilakukan dapat disimpulkan :

1) Nilai Perubahan setelah ditambahkan kapur tohor pada inlet 1 mengalami kenaikan nilai $\mathrm{pH}$, dari $\mathrm{pH} \quad 4,8$ menjadi 9,43 . Sedangkan pada inlet 2 meningkat dari $\mathrm{pH}$ 5,5 menjadi 9,60 dengan persentase kenaikan $\mathrm{pH}$ untuk inlet 1 adalah sebesar $97 \%$ dan inlet 2 adalah sebesar $75 \%$.

2) Sedangkan setelah ditambah fly ash pada inlet 1 mengalami kenaikan dari pH 4,8 menjadi 7,87. Sedangkan pada inlet 2 mengalami kenaikan dari $\mathrm{pH}$ 5,5 menjadi 8,60 dengan persentase kenaikan $\mathrm{pH}$ untuk inlet 1 adalah sebesar $64 \%$ dan inlet 2 adalah sebesar $56 \%$.

3) Kebutuhan penggunaan kapur tohor per bulan sebesar 410,28 Kg/bulan dengan biaya yang harus dikeluarkan sebesar Rp. 2.052.400,-/bulan. Dan penggunaan kebutuhan fly ash sebanyak 2.630,7936 Kg/bulan, untuk biaya pembelian fly ash disesuaikan antara kesepakatan perusahaan dan PLTU terkait.

DAFTAR PUSTAKA

Adha Chairul Wahyu, dkk.2017. Analisis Efektivitas Kapur
Tohor Dan Zeolit

UntukPeningkatan $p H$ Dan

Penurunan Kandungan

LogamFe Dan Cu Pada

Pengolahan Air Asam

Tambang.Jurnal Fakultas

Teknik, November 2017 : 2598 - 7410.

Afrianty Citria, dkk. 2012. Pengolahan

Limbah Air Asam Tambang

Menggunakan Teknologi

Membran Keramik.Junal

Teknik Kimia. No 3 Vol 18.

Page 16-24.

Agmalini Shinta, dkk. 2013. Peningkatan Kualitas Air Rawa Menggunakan Membran

Keramik Berbahan Tanah Liat Alam Dan Abu Terbang Batubara.Junal Teknik Kimia. No 2 Vol 19. Page 59-68.

Basri Hasan, dkk. 2018. Upaya Pemurnian Air Asam Tambang Dengan Menggunakan Membran Keramikn Di PT. Surya Global Makmur, Provinsi Jambi. Tugas Akhir. Sekolah Tinggi Teknologi Industri Padang.

Gautama Rudy Sayoga. 2019. Pembentukan, Pengendalian dan Pengelolaan Air Asam Tambang atau Acid Mine Drainage.

Herlina Ayu, dkk. 2014.Pengaruh Fly Ash dan Kapur Tohor Pada Netralisasi Air Asam Tambang Terhadap Kualitas Air Asam Tambang ( $p H, F e$ dan Mn).Jurnal Ilmu Teknik, Vol 2, No 2 (2014) : 2338 7459

Keputusan Menteri Lingkungan Hidup. Nomor 113 Tahun 2003.TentangBaku Mutu Air 
Limbah Bagi Usaha Dan Atau Kegiatan Pertambangan Batubara.

Nurisman, dkk. 2012.Studi Terhadap Dosis Penggunaan Kapur Tohor (Cao) Pada Proses Pengolahan Air Asam Tambang Pada Kolam Pengendap Lumpur Tambang Air LayaPT. Bukit Asam (Persero), Tbk.Jurnal Teknik Patra Akademika, Juli 2012 : 20895925

Rudy Sayoga Gautama2018. Pembentukan, Pengendalian dan Pengolahan Air Asam Tambang.Institut Teknologi Bandung

Said Nusa Idaman. 2014.Teknologi Pengolahan Air Asam Tambang Batubara Alternatif Pemilihan Teknologi.JAI Vol.7 No. 22014

SNI 6989.11:2004. Tentang Cara Uji Derajat Keasaman ( $p H)$ Dengan Menggunakan Alat $\mathrm{pH}$ Meter.

SNI 6989.3:2004. Tentang Cara Uji Padatan Tersuspensi Total (Total Suspended Soli, TSS) Secara Grafimetri.

SNI 6989.4:2009. Tentang Cara uji besi $(\mathrm{Fe})$ secara spektrofotometri serapan atom (SSA) - Nyala.

SNI 6989.5:2009. Tentang Cara uji Mangan (Mn) secara spektrofotometri serapan atom (SSA) - Nyala.

SNI 6989.59:2008. Tentang Metoda Pengambilan Contoh Air Limbah.
Subriyer Nasir, dkk. 2014. Pengolahan Air Asam Tambang Dengan Menggunakan Membran Keramik Berbahan Tanah Liat, Tepung Jagung Dan Serbuk Besi.Junal Teknik Kimia. No 03 Vol 20, Page 22-30.

Verdiana P. Campaner, dkk 2014. Gheochemistry of Acid Mine Drainage From A Coal Mining Area and Processes Controlling Metal Attenuation In Stream Waters, Southern Brazil.An Acad Bras Cienc (2014) 86 (2)

Wahyu Prinandari Anggriyani, dkk. 2011. Uji Efektifitas Dan Efisiensi Filter Biomassa Menggunakan Sabut Kelapa (cocos nucrifera) Sebagai Bioremoval Untuk Menurunkan Kadar Logam (Cd, $\mathrm{Fe}, \quad \mathrm{Cu}), \quad$ Total Padatan Tersuspensi (TSS) Dan Meningkatkan pH Pada Limbah Air Asam Tambang Batubara. Prestasi.Vol 1 No 1. Page 1-12. 